\title{
Flavopiridol Strongly Sensitizes Canine Lymphoma Cells to TRAIL-induced Apoptosis
}

\author{
ALEKSANDRA PAWLAK ${ }^{1}$, DIEGO DE MIGUEL ${ }^{2,3}$, JUSTYNA KUTKOWSKA ${ }^{4}$, \\ BOŻENA OBMIŃSKA-MRUKOWICZ ${ }^{1}$, ANDRZEJ RAPAK ${ }^{4}$ and LUIS MARTINEZ LOSTAO ${ }^{5,6,7,8}$ \\ ${ }^{1}$ Department of Pharmacology and Toxicology, Faculty of Veterinary Medicine, \\ Wrocław University of Environmental and Life Sciences, Wroclaw, Poland; \\ ${ }^{2}$ Departamento de Bioquímica, Biología Molecular y Celular, Universidad de Zaragoza, Zaragoza, Spain; \\ ${ }^{3}$ Centre for Cell Death, Cancer, and Inflammation (CCCI), UCL \\ Cancer Institute, University College London, London, U.K.; \\ ${ }^{4}$ Laboratory of Tumor Molecular Immunobiology, Ludwik Hirszfeld \\ Institute of Immunology and Experimental Therapy, Wroclaw, Poland; \\ ${ }^{5}$ Servicio de Inmunología, Hospital Clínico Universitario Lozano Blesa, Zaragoza, Spain; \\ ${ }^{6}$ Instituto de Investigación Sanitaria de Aragón (IIS Aragón), Instituto de Salud Carlos III, Zaragoza, Spain; \\ ${ }^{7}$ Departamento de Microbiología, Medicina Preventiva y Salud Pública, Universidad de Zaragoza, Zaragoza, Spain; \\ ${ }^{8}$ Instituto de Nanociencia de Aragón (INA), C/ Matiano Esquillor Gomez, Zaragoza, Spain
}

\begin{abstract}
Background/Aim: Targeting the extrinsic apoptotic pathway is an interesting option for anticancer therapy. A protein which such ability is Apo2 ligand, also known as TNF-related apoptosis-inducing ligand (TRAIL). The aim of this study was to examine the possibility of sensitizing resistant CLBL-1 canine lymphoma cells to TRAIL-induced apoptosis by using flavopiridol (FVP) a cyclin-dependent kinase inhibitor (CDKs). Materials and Methods: The CLBL-1 (canine B-cell lymphoma cell line) was used in the study. The effect of FVP and TRAIL treatment on apoptosis induction was assessed by flow cytometry and western blot. Results: Although canine lymphoma cells were resistant to TRAIL-induced apoptosis, combination of this death ligand with FVP was able to overcome TRAIL resistance of CLBL-1 lymphoma cells. Conclusion: Our results demonstrated that although canine lymphoma cells were resistant to TRAIL-induced apoptosis, combination of this death ligand with FVP was able to overcome TRAIL resistance of CLBL-1 lymphoma cell line. Although further investigation is required to deepen the
\end{abstract}

Correspondence to: Aleksandra Pawlak, Department of Pharmacology and Toxicology, Faculty of Veterinary Medicine, Wrocław University of Environmental and Life Sciences, C.K. Norwida 31, 50-375, Wrocław, Poland. Tel: +48 713205403, e-mail: aleksandra.pawlak@upwr.edu.pl

Key Words: TRAIL, flavopiridol, apoptosis, canine lymphoma cells. knowledge of TRAIL as an antitumor agent in canine cancers, our results open the door to future use of TRAILbased treatment strategies in veterinary oncology.

Apo2 ligand, also known as TNF-related apoptosis-inducing ligand (TRAIL), belongs to the tumor necrosis factor (TNF) family of proteins. It is capable of inducing apoptosis through activation of the extrinsic apoptotic pathway $(1,2)$. Physiologically, this ligand is expressed by the immune system cells, mainly by T cells, NK cells and macrophages, and plays an important role in immune response regulation $(3,4)$. Numerous studies indicate that TRAIL is able to induce apoptosis in different types of neoplastic cell lines, while most normal cells are resistant to this ligand (5). For that reason, since its first description TRAIL has been considered as a promising anticancer agent in humans (6-8). In this line, TRAIL can also be an interesting antitumor agent in veterinary medicine, where high toxicity of novel anticancer drugs is a crucial problem.

In humans, TRAIL can bind to four membrane-bound TRAIL receptors (TRAIL-R):TRAIL-R1/DR4, TRAILR2/DR5, TRAIL-R3/DcR1 and TRAIL-R4/DcR2 and also to one soluble receptor called osteoprotegerin (OPG) (9-11). The receptors DR4 and DR5 are fully functional, and upon ligation with TRAIL transmit an apoptotic signal via trimerization of their intracellular death domains, which induce the formation of the so-called DISC (Death Inducing Signalling Complex). The decoy receptors (DcR1 and DcR2) are also expressed on the cell surface but they lack functional death domains, hence 
being unable to initiate apoptosis (12). Finally, TRAIL can bind to the soluble receptor OPG. This receptor, though expressing a death domain, it lacks a canonical transmembrane domain, therefore functioning only as a secreted decoy receptor (13). However, intriguingly there are reports in the literature proving surface expression of OPG in certain cell types, namely lymphoid cells and osteoclasts $(14,15)$. Although the means by which OPG attaches to the cell surface remain unclear, these reports suggest a functional role for that receptor in those cell types. Whether that functional role involves induction of cell death or activation of pro-inflammatory pathways (e.g. NF- $\varkappa \mathrm{B}$ ) is yet to be elucidated. Interestingly, the expression of TRAIL receptors and their role in canine species remain unclear. So far, only one potential canine TRAIL receptor ortholog (osteoprotegerin, TNFRSF11B) could be identified by screening the dog genome assembly (http://www.ensembl.org/Canis_familiaris/index.html). Although studies in other species have shown that increased expression of TNFRSF11B can protect cancer cells from TRAIL-induced apoptosis (16) it is possible that the cell surface expressed canine TNFRSF11B would be able to transduce an apoptotic signal. In this regard, Elders and colleagues observed that the mRNA for TNFRSF11B was found in TRAIL susceptible canine cancer cell line C2 but not in resistant MDCK cells (17), somehow suggesting a specific pro-apoptotic role for TNFRSF11B in canine cells.

The potential of TRAIL for veterinary medicine has only been slightly investigated, being just a few reports concerning this topic (17-20). Some of those studies used human recombinant TRAIL on different canine cell lines of mammary gland tumor (P114), osteosarcoma (D-17), and mastocytoma $(\mathrm{C}-2)(17,18)$. In this regard, studies on sensitivity of canine mastocytoma cell line (C2) to human TRAIL showed that $\mathrm{C} 2$ cells were more sensitive to the proapoptotic effects of the ligand than normal canine kidney cells (MDCK). In another study by Rong et al., the authors synthesized canine TRAIL and found it to bear a high homology with the human protein $(81.3 \%$ sequence homology). Interestingly, they also showed that the canine protein was more effective in inducing apoptosis in human neoplastic cells than human TRAIL protein in canine cancer cells (19). During that time, Spee et al. (18) reported a possibility of using TRAIL in inducing apoptosis in osteosarcoma cells, mammary gland tumor or canine bile duct epithelial cells and discussed the role of the X-linked inhibitor of apoptosis protein (XIAP) in resistance to the ligand which also may be a problem in dogs therapy.

Therapeutic strategies based on Apo2L/TRAIL involve the use of soluble recombinant TRAIL or monoclonal agonistic antibodies against DR4 and DR5 receptors $(21,22)$. However, although safe, the only recombinant version of TRAIL approved to be used in the clinic has shown limited efficacy in phase II clinical trials $(6,23)$. For that reason, other highly bioactive versions of TRAIL $(7,24,25)$ or combined therapies $(26,27)$ are required to overcome TRAIL resistance of some cancer cells. Regarding combined therapies, a wide variety of antitumor agents such as cytostatics, tyrosine kinase inhibitors, histone deacetylase inhibitors and proteasome inhibitors have been used in combination with TRAIL (28-30). Among the different strategies followed to sensitize to TRAIL induced apoptosis, inhibition of cyclindependent kinases (CDKs) has shown exceptionally promising results. In this regard, the pan-CDK inhibitor flavopiridol (FVP) $(31,32)$ has been widely used in combination with TRAIL (33-39). Although FVP can block different CDKs, the specific mechanism by which it sensitizes tumor cells to TRAIL-induced apoptosis is mainly through inhibition of mRNA production. FVP inhibits CDK9, a component of the $\mathrm{p}-\mathrm{TEFb}$ (positive transcription elongation factor b), therefore blocking DNA transcription, and ultimately protein expression. This blockage primarily affects expression of short half-life proteins involved in regulation of apoptosis such as cFLIP, XIAP or Mcl-1 (33-35, 37-39). Besides, FVP has been described to increase surface expression of the pro-apoptotic TRAIL receptor DR5 (40).

Although the antitumor activity of FVP alone has already been explored in dogs (41), to our knowledge the combination of TRAIL with FVP has not yet been analyzed in canine tumors. Hence, we decided to examine the TRAILsensitizing activity of the aforementioned compound in canine lymphoma. Since the most common type of lymphoma in dogs is diffuse large B-cell lymphoma, we chose to test the CLBL-1 cell line, derived from a dog with said type of lymphoma $(42,43)$.

\section{Materials and Methods}

Chemicals and reagents. Soluble TRAIL (thereafter hTRAIL, corresponding to amino acids 95-281 cloned into the pET-28c plasmid -Novagen) was kindly provided by Dr. M. MacFarlane (44). Blocking anti-human TRAIL mAb clone RIK2 were from BD Biosciences (San Jose, CA, USA). Flavopiridol (FVP), fetal bovine serum (FBS), L-glutamine, penicillin and streptomycin solution and propidium iodide were purchased from Sigma-Aldrich (Steinheim, Germany). Annexin V FITC was purchased from Immunostep (Salamanca, Spain) and CellEvent ${ }^{\mathrm{TM}}$ Caspase-3/7 Green Flow Cytometry Assay Kit from Molecular Probes (Eugene, OR, USA). Phosphate buffered saline (PBS), and RPMI 1640 culture medium were obtained from the Institute of Immunology and Experimental Therapy, Wrocław, Poland. Caspase-Family Inhibitor Z-VAD-FMK was from BioVision (Milpitas, CA, USA).

Cell lines and cell cultures. The CLBL-1 (canine B-cell lymphoma cell line) obtained from Barbara C. Ruetgen from Institute of Immunology, Department of Pathobiology of the University of Veterinary Medicine in Vienna was used in the study (43). CLBL-1 cells were maintained in RPMI 1640 culture medium supplemented with $2 \mathrm{mM} \mathrm{L}$-glutamine, $100 \mathrm{U} / \mathrm{mL}$ penicillin and $100 \mu \mathrm{g} / \mathrm{mL}$ streptomycin and $10 \%$ heat-inactivated fetal bovine serum (FBS). The culture was maintained in the atmosphere of $5 \% \mathrm{CO}_{2}$ and $95 \%$ 
humidified air, at $37^{\circ} \mathrm{C}$. The cells were cultured in $25 \mathrm{~cm}^{2}$ cell culture flask (Corning, NY, USA) and subcultivated every other day to keep at optimal density.

Cell death analysis. Staining with propidium iodide (PI) was carried out to determine cell death. Briefly, $75 \times 10^{4}$ cells per well were seeded in a 96-well-plate (TPP, Trasadingen, Switzerland) and hTRAIL or FVP were added at the final concentration range of 250$1000 \mathrm{ng} / \mathrm{ml}(250 \mathrm{ng} / \mathrm{ml}, 500 \mathrm{ng} / \mathrm{ml}, 1000 \mathrm{ng} / \mathrm{ml})$ or of $50-200 \mathrm{nM}$ $(50 \mathrm{nM}, 100 \mathrm{nM}, 200 \mathrm{nM})$ respectively for $24 \mathrm{~h}$. After that, cells were harvested and washed twice in PBS, transferred into cytometric tubes and stained with PI (final concentration of $1 \mu \mathrm{g} / \mathrm{ml})$. Cell death was analyzed using FACS Calibur cytometer and CellQuest 3.lf. software (Becton Dickinson, Biosciences, San Jose, CA, USA).

Quantification of apoptosis. Phosphatidyl-serine exposure on cell surface is a characteristic event in apoptotic cell death and was analyzed to quantify apoptosis. Binding of annexin $\mathrm{V}$ to phosphatidylserine translocated to the outer cell membrane was assessed by flow cytometry. Briefly, $75 \times 10^{4}$ cells were treated with the tested compounds (hTRAIL, FVP or its combination). For combined treatment, cells were incubated with FVP for $6 \mathrm{~h}$ and then hTRAIL was added and cells were incubated for further $24 \mathrm{~h}$. After harvesting the cells and washing them twice with cold PBS, they were suspended in a binding buffer and stained with annexin V-FITC for $10 \mathrm{~min}$ at room temperature. After that, apoptosis quantification was carried out using FACS Calibur cytometer and CellQuest 3.lf. software (Becton Dickinson, Biosciences, San Jose, CA, USA). As a control, cells were preincubated for 1 hour with anti-human TRAIL mAb $(250 \mathrm{ng} / \mathrm{mL}$, clone RIK2, BD Biosciences, San Jose, CA, USA) or the pan-caspase inhibitor Z-VAD-fmk (30 $\mu \mathrm{M}$, BioVision, Milpitas, CA, USA).

Apoptosis is characterized by caspase activation. For that, analysis of caspase-3/7 activation was performed using CellEvent ${ }^{\mathrm{TM}}$ Caspase-3/7 Green Flow Cytometry Assay Kit (ThermoFisher Scientific, Waltham, MA, USA). Briefly, after $24 \mathrm{~h}$, cells were harvested and washed twice in PBS, transferred into cytometric tubes and stained with CellEvent ${ }^{\circledR}$ Caspase-3/7 Green Detection Reagent for $30 \mathrm{~min}$ at $37^{\circ} \mathrm{C}$. Before flow cytometry analysis, SYTOX $^{\circledR}$ AADvanced $^{\mathrm{TM}}$ dead cell stain solution was added according to the manufacturer's instructions. Samples were analyzed using FACS Calibur cytometer and CellQuest 3.lf. software (Becton Dickinson, Biosciences San Jose, CA, USA).

Western blot analysis. A total of $5 \times 10^{6}$ cells were treated with tested compounds and their combination for $24 \mathrm{~h}$ as described above. After incubation, cells were rinsed with cold PBS, suspended in the lysis buffer $(50 \mathrm{mM}$ Tris- $\mathrm{HCl} \mathrm{pH} 7.5,100 \mathrm{mM} \mathrm{NaCl}, 1 \% \mathrm{NP}-40$ and protease inhibitors set) and incubated for $20 \mathrm{~min}$ on ice. Then, cells were centrifuged at $10,000 \mathrm{rpm}$ at $4^{\circ} \mathrm{C}$ for 10 minand sodium dodecyl sulfate (SDS) sample buffer was added to clear supernatants. Samples were boiled at $95^{\circ} \mathrm{C}$ for $5 \mathrm{~min}$ and subjected to SDS-PAGE on $10-15 \%$ gel. The resolved proteins were transferred to PVDF membrane (Millipore, Billerica, MA, USA), using Semidry Transfer Cell (BIO-RAD, Hercules, CA, USA). After that, the membrane was blocked overnight with $1 \%$ casein in TBS at $4^{\circ} \mathrm{C}$, and then incubated with $1-2 \mu \mathrm{g} / \mathrm{ml}$ of primary antibody at room temperature for 1 hour, followed by secondary horseradish peroxidase-labeled antibody (DAKO, Glostrup, Denmark). The bound antibodies were visualized using ECL blotting detection system (Thermoscientific, Waltham, MA, USA). Canine peripheral blood mononuclear cells (PBMC) obtained from healthy dog were used as a control. Anti-BID (PAB0238) antibody was from Abnova Corporation (Taipei City, Taiwan). The other antibodies were from Santa Cruz Biotechnology (CA, USA): PARP (H-250), Bcl-2 (C-2), Bcl-xl (S-18), Mcl-1 (S-19), XIAP (H-202), cFLIPs/l (G-11), caspase 8 (H-134), caspase $9(\mathrm{H}-170)$, Actin (C-4).

Statistical analysis. All data are shown as the mean \pm standard deviations (SD) of four independent experiments. Statistical differences were analyzed using Student's $t$-test for normally distributed values and one-way ANOVA followed by Tukey's multiple comparison test were used to test statistical differences among treatment groups. The results were considered significant when $p<0.05$.

\section{Results}

Canine lymphoma CLBL-1 cells are resistant to recombinant TRAIL. First of all, we wanted to analyze the cytotoxic effect of human soluble TRAIL (hTRAIL hereafter) in the canine lymphoma cell line CLBL-1 (Figure 1). Although the effect of hTRAIL on CLBL-1 cell line was studied using a wide of concentrations up to $1,000 \mathrm{ng} / \mathrm{ml}$, no cytotoxic effect of the death ligand could be observed. Percentage of dead cells after treatment with increasing TRAIL concentration was not statistically different from the control and the values ranged below $6 \%$ of dead cells. Even after prolonged exposition up to 72 hours with a concentration of hTRAIL of $3000 \mathrm{ng} / \mathrm{mL}$, CLBL-1 cells remain unaffected (data not shown) indicating that these cells are completely resistant to hTRAIL.

Flavopiridol sensitizes CLBL-1 cells to apoptosis induced by hTRAIL. As mentioned above, flavopiridol (FVP) has been shown to be a strong hTRAIL sensitizer in different human cancer cells (33-35, 37-39). For that reason, we sought to sensitize CLBL-1 cells by treating them with FVP in combination with hTRAIL. As shown in Figure 2, FVP alone showed remarkable cytotoxicity on CLBL-1 cells. However, combination of hTRAIL with FVP showed a higher cytotoxic effect that FVP alone. Importantly, those differences were statistically significant for the combination of hTRAIL with both FVP concentrations, $100 \mathrm{nM}$ or $200 \mathrm{nM}$. Although the cell death induced by FVP alone at $200 \mathrm{ng} / \mathrm{ml}$ was too high to draw any conclusion, the TRAIL sensitizing effect of the FVP dose of $100 \mathrm{nM}$ strongly suggested that hTRAIL may be cytotoxic on CLBL-1 cell line, but its cytotoxic effect is blocked by a molecular mechanism, which is, at least partially, released by FVP.

The next step was to characterize the type of cell death that the combination of hTRAIL with FVP induced in CLBL-1 cells. Annexin V staining indicated that both FPV alone or in combination with TRAIL induced phosphatidylserine translocation in CLBL-1 cells, a typical feature of apoptosis (Figure 3). Accordingly, preincubation with the 


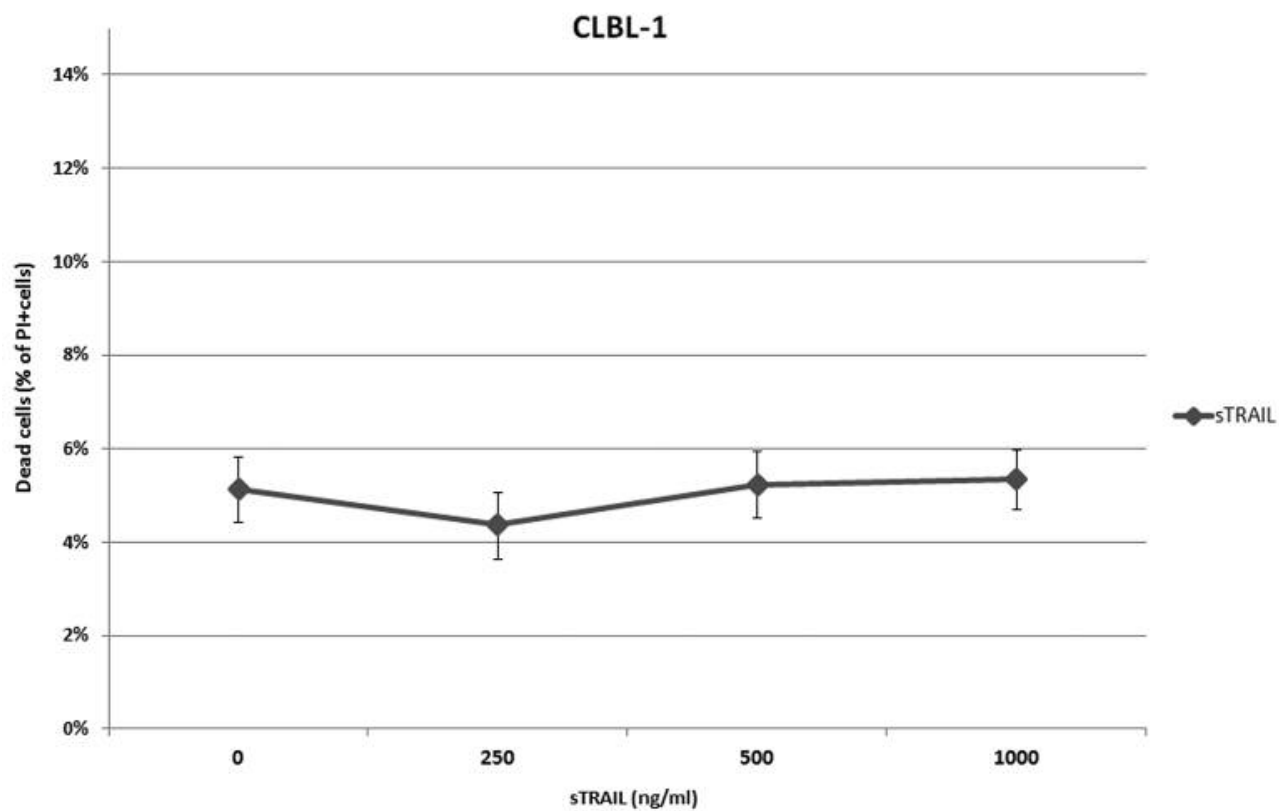

Figure 1. Cell death induction by hTRAIL on CLBl-1 cell line. Cells were treated with hTRAIL at indicated concentrations for 24 h. After that, cell death was measured by propidium iodide (PI) staining. Graph shows the mean $\pm S D$ of at least four independent experiments.

pan-caspase inhibitor Z-VAD-fmk abrogated cell death, resulting in a marked reduction of apoptosis in CLBL-1 cells to levels comparable to the control $(17.45 \pm 4.13 \%)$. Importantly, preincubation of CLBL-1 cells with the blocking anti-human TRAIL monoclonal antibody (clone RIK2) suppressed the synergistic effect observed when both agents were used in combination, reducing apoptosis to the same level observed when FVP was used alone, proving that the observed cytotoxic effect is TRAIL dependent.

As indicated above, the pan-caspase inhibitor Z-VADfmk fully abrogated cell death induced by the combined treatment indicating that caspase activation is necessary for the cytotoxicity induced by hTRAIL plus FVP. To further evaluate that, caspase 3/7 activation was assessed in CLBL1 cells treated with the combination of hTRAIL and FVP (Figure 4). As observed in Figure 4, combination of hTRAIL with FPV induced the strongest activation of the effector caspases 3 and $-7 \quad(64.60 \pm 1.41 \%$ of cells). Remarkably, this caspase activation perfectly correlated with phosphatidyl-serine translocation, being the percentages almost identical. Again, the pan-caspase inhibitor Z-VAD-fmk effectively blocked the proapoptotic effect of the combined treatment $(6.30 \pm 2.36 \%$ of cells with active form of caspase-3/7). Finally, preincubation of CLBL-1 cells with the blocking anti-human TRAIL monoclonal antibody (clone RIK2) suppressed the synergistic effect observed when both drugs were used in combination reducing caspase-3/7 activation at same level as that observed with FVP alone.

Flavopiridol induced cFLIP degradation and Bid activation in CLBL-1 cells. To better understand the way in which FVP sensitized to TRAIL-induced apoptosis in the canine lymphoma CLBL-1 cell line, changes of the expression pattern of different key proteins was analyzed by Western blot after different treatments (Figure 5). CLBL-1 cells were characterized by presenting a chronic activation of nuclear factor-kappa $\mathrm{B}$ (NF$\mathrm{kB})$ as well as an increased expression of the anti-apoptotic members of the Bcl-2 family Bcl-2, Bcl-xL and Mcl-1. Interestingly, CLBL-1 cells also showed certain overexpression of the pro-apoptotic Bcl-2 family member Bid, which could sensitize cells to TRAIL-induced apoptosis (45). When CLBL1 cells were treated with FVP alone for 6 hours, no changes in the expression levels of Bcl-2, Bcl-xL, Mcl-1 and XIAP (Xlinked of apoptosis protein) could be noticed. Similarly, the combined treatment of FVP with TRAIL did not show any effect on those same proteins either. However, it is noteworthy that the combination of FVP with hTRAIL did induce a strong reduction of cFLIP levels, which correlated with a stronger activation of caspase-8. Moreover, this increased activation of caspase- 8 correlated with a more robust cleavage of Bid, which was indeed in accordance with the observed overexpression of this BH3only protein in these cells. Consequently, the mitochondrial apoptotic machinery appeared to be also more active after 


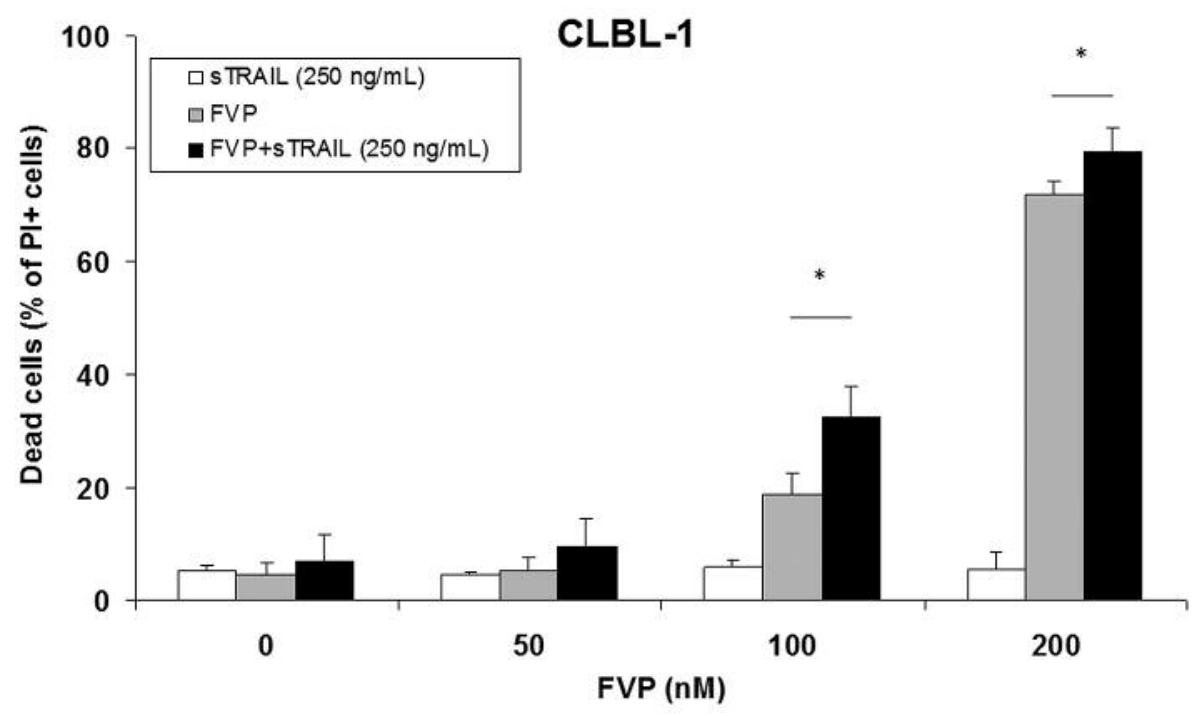

Figure 2. Cell death induction by combined treatment of hTRAIL with FVP on CLBL-1 cell line. Cells were treated with hTRAIL at $250 \mathrm{ng} / \mathrm{ml}$ alone or after previous treatment with FVP $(6 \mathrm{~h})$ as indicated concentrations for $24 \mathrm{~h}$. After that, cell death was measured by propidium iodide (PI) staining. Graph shows the mean $\pm S D$ of four independent experiments. ${ }^{*} p<0.05$.

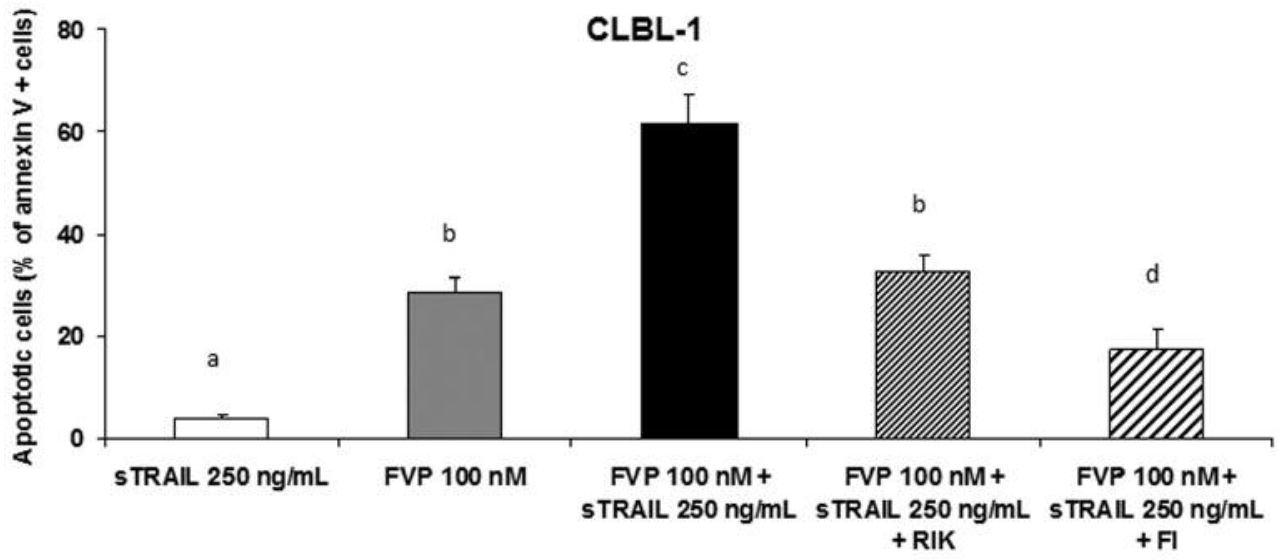

Figure 3. Apoptosis induction by combined treatment of hTRAIL with FVP on the CLBl-1 cell line. Cells were treated with hTRAIL (250 ng/ml), with FVP (100 nM) or with the combination of hTRAIL and FVP. Combined treatment was also performed using hTRAIL and FVP previously preincubated with the anti-TRAIL blocking $\mathrm{mAb}$, RIK2 (RIK, $250 \mathrm{ng} / \mathrm{ml})$, or the pan-caspase inhibitor Z-VAD-fmk (FI, $30 \mu M)$. Apoptosis was measured by annexin-V staining after $24 \mathrm{~h}$. Graph shows the mean $\pm S D$ of four independent experiments. The results were considered significant when $p<0.05$. Values without common letters $(a, b, c)$ in the superscript differ statistically.

treatment with FVP+hTRAIL, as reflected by the increased cleavage of caspase-9. Finally, the increased cleavage of PARP1 , a known substrate of the executioner caspase-3, proved the overall superior pro-apoptotic potential of FVP+hTRAIL. Altogether the combined treatment showed an improved proapoptotic potential as compared with hTRAIL alone.

\section{Discussion}

Since its first description, TRAIL was considered as a promising potential antitumor agent in humans due to its ability to induce apoptosis in cancer cells while not affecting normal cells (6-8). However, the potential of TRAIL for 
A

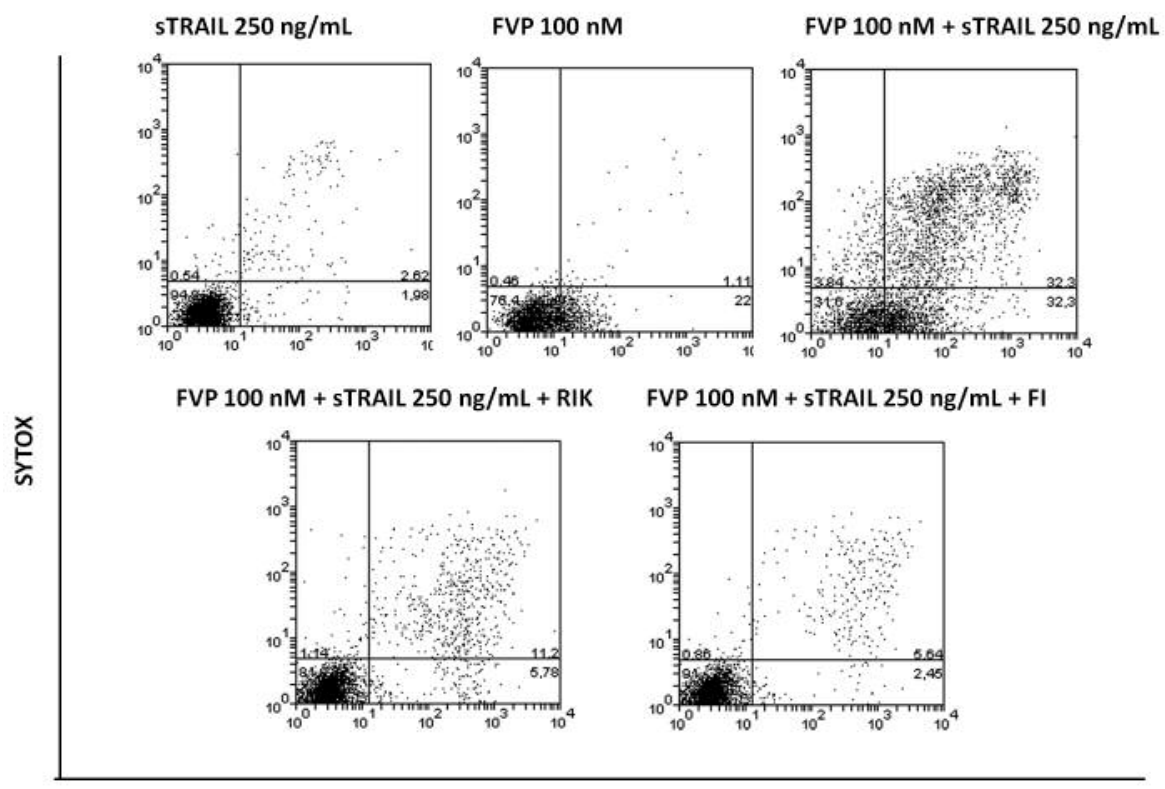

CASPASE $3 / 7$

B

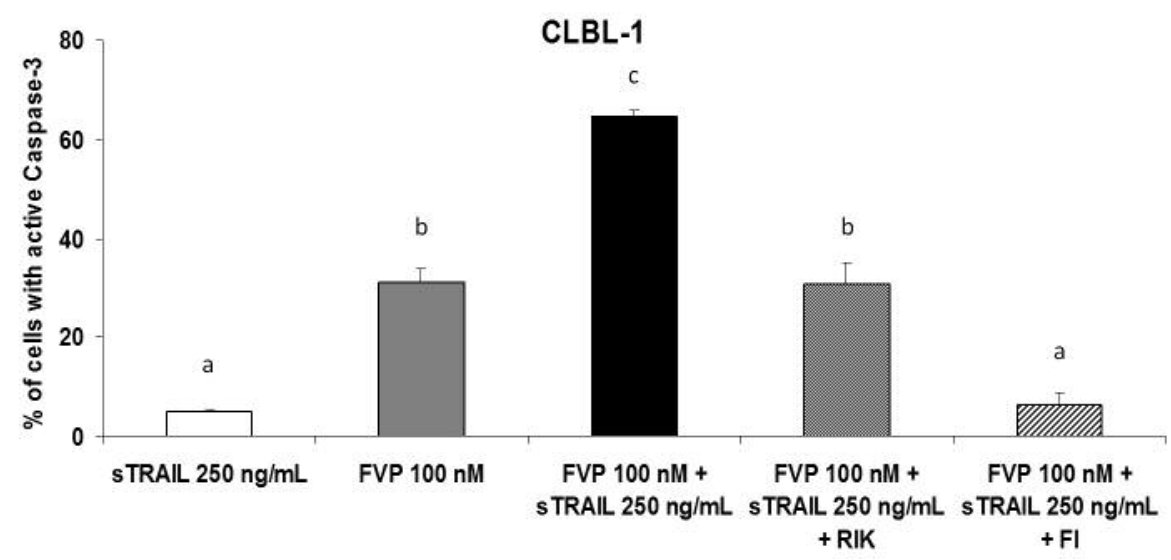

Figure 4. Caspase-3/7 activation by combined treatment of hTRAIL with FVP on the CLBl-1 cell line. Cells were treated with hTRAIL (250 ng/ml), with FVP (100 nM) or with the combination of hTRAIL and FVP. Combined treatment was also performed using hTRAIL and FVP previously preincubated with the anti-TRAIL blocking $m A b, R I K 2$ (RIK, $250 \mathrm{ng} / \mathrm{ml})$, or the pan-caspase inhibitor $z$-VAD-fmk (FI, $30 \mu \mathrm{M})$. After $24 \mathrm{~h}$, caspase-3/7 activation was measured using CellEvent ${ }^{T M}$ Caspase-3/7 Green Flow Cytometry Assay Kit. (A) Dot plots obtained in one representative experiment showing caspase-3/7 activation (X-axis) and cell death (Y-axis). (B) Graph shows the mean $\pm S D$ of four independent experiments. The results were considered significant when $p<0.05$. Values without common letters $(a, b, c)$ in the superscript differ statistically.

veterinary cancers has only been marginally investigated (1720). Moreover, no scientific work exploring the possibility of combining TRAIL with sensitizing agents in a veterinary context has been reported. In the present work, we have analyzed the combined effect of TRAIL with the sensitizing agent FVP in the canine lymphoma cell line CLBL-1. Our results clearly demonstrated that the canine CLBL-1 cells are resistant to recombinant human TRAIL-induced apoptosis in normal conditions. This could have been attributed to a lack of cross reactivity between the human ligand and the canine receptor. However, this seemed unlikely providing that previous studies already reported sensitivity of different 


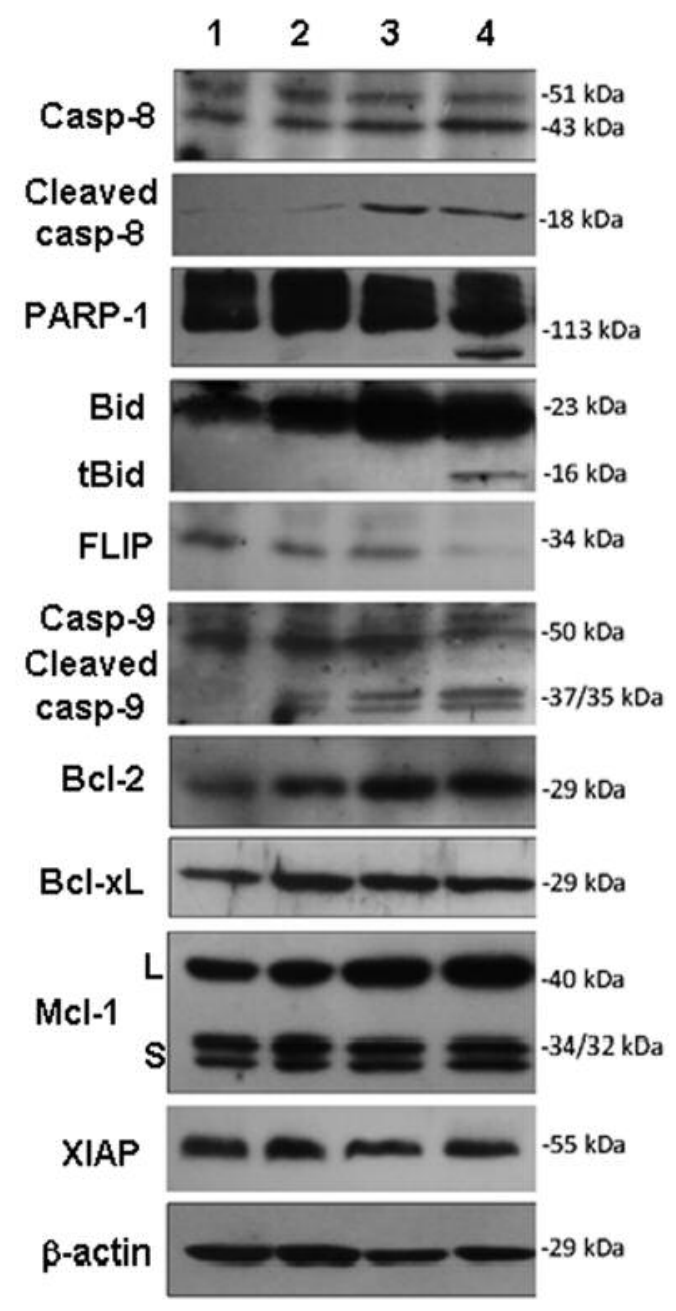

\section{Control \\ 2. sTRAIL $250 \mathrm{ng} / \mathrm{mL}$ \\ 3. FVP $100 \mathrm{nM}$ \\ 4. sTRAIL $250 \mathrm{ng} / \mathrm{mL}+$ FVP $100 \mathrm{nM}$}

Figure 5. Analysis of protein expression after combined treatment of hTRAIL with FVP on CLBl-1 cell line. Protein expression of the indicated proteins were analyzed by Western blot in untreated CLBL-1 cells (line 1) and treated with hTRAIL (250 $\mathrm{ng} / \mathrm{ml})$ (line 2), with FVP $(100 \mathrm{nM})$ (line 3) or with the combination of hTRAIL and FVP (line 4). $\beta$-actin levels were used as a control for equal protein loading.

canine cancer cell lines to human recombinant TRAIL (17, 18) suggesting that the TRAIL resistance observed in CLBL1 cells would most likely be due to an inherent resistance mechanism. Therefore, we tried to sensitize CLBL-1 cells to TRAIL-induced apoptosis using flavopiridol (FVP), a wellknown TRAIL-induced apoptosis sensitizing agent.
FVP is well known for its strong inhibitory effect on cyclin-dependent kinases (CDKs). Nevertheless, its antitumor activity is not only limited to cell cycle arrest and apoptosis induction. For example, FVP exhibits also antiproliferative activity most likely through direct and indirect inhibition of EGFR receptor activation and/or a direct inhibition of other kinases involved in the signal transduction pathway (pp60 Src, PKC and Erk-1) (46). The possibility of using of FVP in veterinary oncology has also been explored. It was demonstrated that FVP at a concentration of $400 \mathrm{nM}$ was able to induced apoptosis in many different canine lymphoma cell lines (CLBL-1, Ema, CL-1, GL-1, UL-1, CLGL90, Nody-1 and 17-71) (41). Accordingly, we found that CLBL-1 cells showed a remarkable sensitivity to FVP-induced cell death, being able to induce about $70 \%$ of dead cells after $24 \mathrm{~h}$ exposure at $200 \mathrm{nM}$, and around $30 \%$ when used at $100 \mathrm{nM}$. Moreover, the cell death observed was an apoptotic process, showing phosphatidyl-serine exposure and caspase activation.

However, combination of TRAIL with FVP showed a synergistic effect on CLBL-1 cells, improving the cytotoxicity of both FVP and TRAIL alone. Although CLBL-1 cells were completely resistant to TRAIL-induced cell death even at the highest doses used, combination of this death ligand with FVP sensitized canine lymphoma cells to TRAIL. In this line, preincubation with the blocking anti-TRAIL monoclonal antibody RIK2 reverted the cell death levels to those observed with FVP alone, demonstrating the TRAIL specificity of the synergistic cytotoxic effect. Moreover, the combination of TRAIL with FVP induced a canonical apoptotic cell death, with phosphatidyl-serine exposure and caspase activation. In this regard, it should be noted that zVAD completely abrogated the cell death observed, discarding any other mode of TRAIL-induced cell death such as necroptosis (47). In order to better understand how FVP sensitized cells to TRAIL-induced apoptosis, we analyzed the expression of a wide range of proteins involved in TRAIL signaling regulation after treatment with FVP alone, TRAIL alone or the combination of both.

Several studies have previously described the synergistic potential of FVP and TRAIL in human cancer cells $(33,35$, 40, 48). However, the mechanism behind this sensitizing effect has not been yet clearly demonstrated. Being a panCDK inhibitor, in addition to blocking cell-cycle related CDKs, FVP also exerts an inhibitory effect on CDK9 and CDK7, which form part of the P-TEFb (positive translation elongation factor $\mathrm{b}$ ), a key component of the translation machinery (49). In this line, Lemke and collaborators (6) described that SNS-032, a CDK inhibitor with high specificity for CDK9, exerted a strong TRAIL sensitizing effect by inducing a strong reduction of the short-lived proteins Mcl-1 and cFLIP, as a result of the inhibition of their de novo expression by blockage of protein translation. 


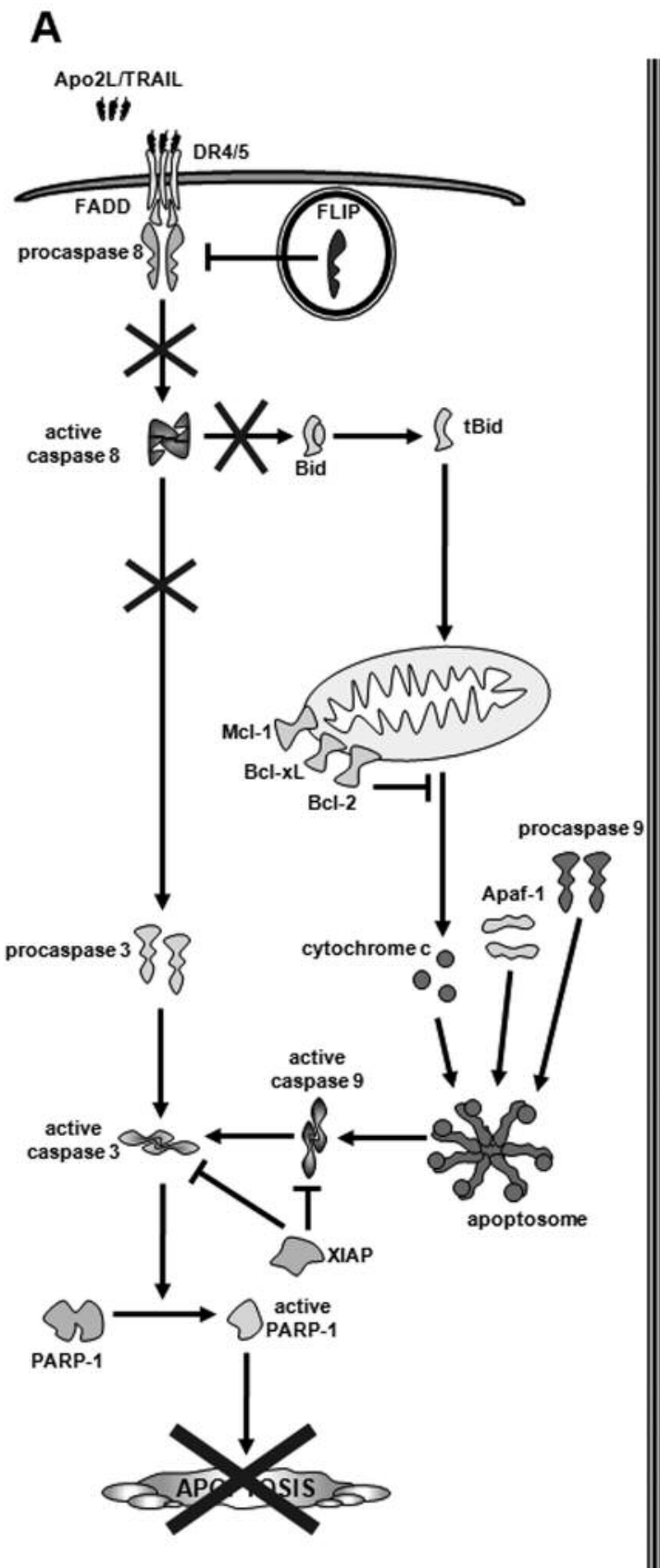

B

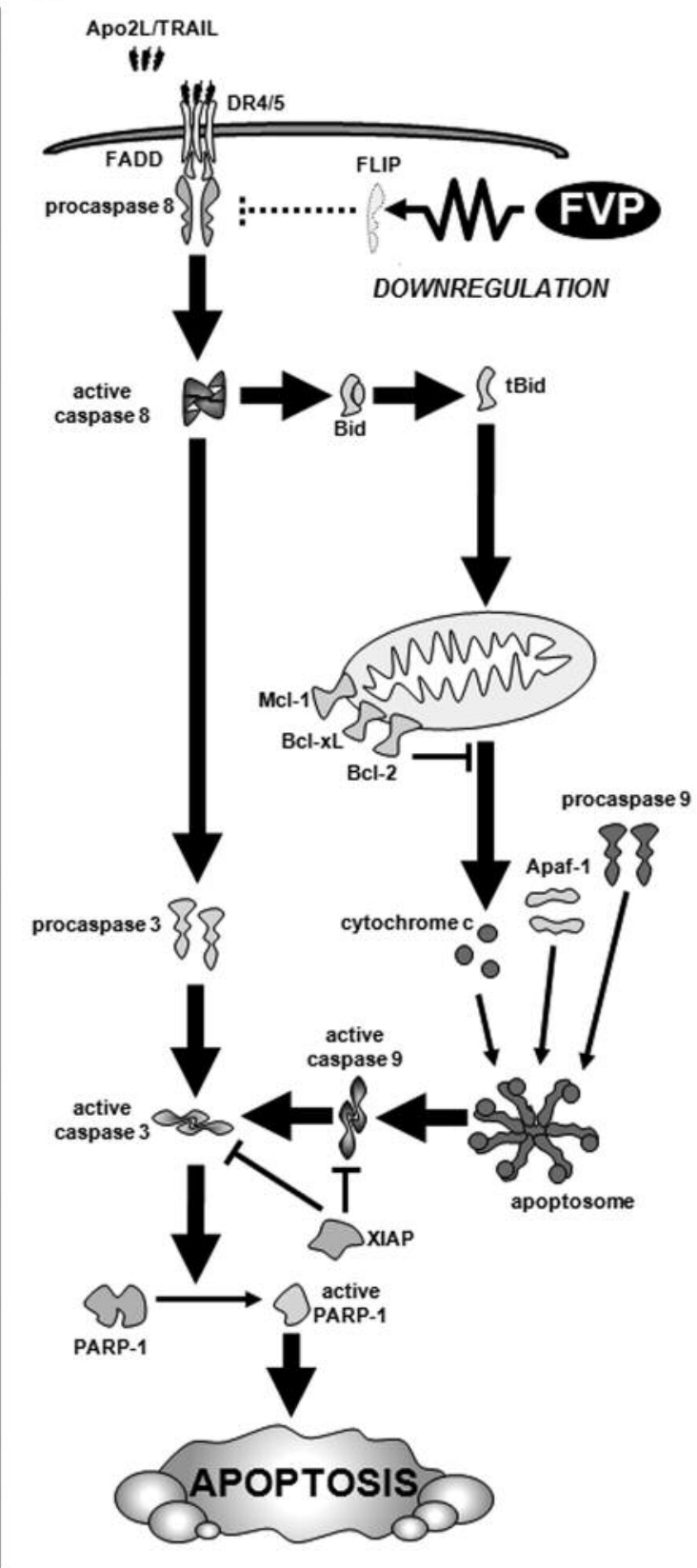

Figure 6. Schematic representation of the proposed model for the increase of cytotoxicity of combined treatment of hTRAIL with FVP. Experimental data obtained lead us to propose the presented model. In the case of hTRAIL alone (left), anti-apoptotic protein cFLIP blocks activation of the apoptotic signalling through extrinsic pathway at its initial step. When hTRAIL acts in association with FVP (right), FVP promoted the downregulation of cFLIP allowing the activation of the apical caspase-8. Activated caspase-8 triggers activation of caspase-3 in a direct manner and also activates BH-3 proapoptotic protein Bid which in turn activated the mithochodrial amplification loop of apoptosis leading to caspase-9 activation. Finally, activated caspase-3 (directly by activated caspase-8 and through mitochondrial apoptotic pathway) induced PARP-1 degradation leading to apoptosis.

Therefore, it is likely that the TRAIL-sensitizing effect exerted by FVP is at least in part due to CDK9/7 inhibition. Nevertheless, other TRAIL-sensitizing functional effects such as increased surface expression of DR5 have also been described for FVP besides its inhibitory effect on proteintranslation (40).

Surprisingly, no changes in the expression level of XIAP, Mcl-1, Bcl-2 and Bcl-xL proteins could be observed after 
treatment with either FVP alone or with the combination of FVP and hTRAIL, contrarily to the aforementioned previous studies $(30,33,35,37)$. In any case, we did observe a clear reduction of the anti-apoptotic protein cFLIP when TRAIL and FVP were used in combination. Considering the potent inhibitory effect of cFLIP on caspase- 8 activation (50), this downregulation would most likely be directly linked to the TRAIL-sensitizing effect of FVP. Interestingly, cleavage of the pro-apoptotic $\mathrm{BH}-3$-only protein $\mathrm{Bid}$ and a clear activation of caspase-9 were also observed upon FVP+hTRAIL treatment. This, together with the stronger caspase-3 activation and PARP-1 cleavage detected, proved that FVP driven TRAIL sensitization relied on an increased activation of both the extrinsic and the intrinsic branches of the apoptotic machinery. Taking all these into consideration, we propose a model to explain the synergistic effect of FVP+hTRAIL (Figure 6). Thus, in normal conditions the activation of caspase- 8 in CLBL-1 cells upon TRAIL stimulation would be blocked mainly by cFLIP at the DISC level (Figure 6A). However, the inhibition of protein transcription exerted by FVP would provoke a halt of the turnover of cFLIP, ultimately leading to a reduction of its expression. This effective downregulation of cFLIP would allow the activation of caspase- 8 (Figure 6B). Active caspase- 8 , in turn, can directly activate caspase- 3 in a direct manner, but it also cleaves the pro-apoptotic BH3-only protein Bid, generating truncated Bid (tBid). Truncated Bid triggers activation of the mitochondrial loop of amplification leading to activation of caspase-9. Interestingly, in this regard, according to our data CLBL-1 cells appear to be type II cells in relation to TRAIL susceptibility (51). Finally, caspase- 3 was activated directly by both caspase- 8 and by caspase- 9 ultimately unleashing the apoptotic process.

\section{Conclusion}

TRAIL is able to induce apoptosis in a wide variety of tumor cells while sparing most normal cells, therefore investigating the possibility of the use of TRAIL still remains in the range of researcher's interest. Targeting of the extrinsic apoptotic pathway for anticancer therapy is uniquely attractive for several reasons including facts that death receptors are widely expressed in tumors and that proapoptotic receptors activate caspases and induce apoptosis regardless of the p53 status of cancer cells. Therefore, it seems that the research on sensitization of cells initially resistant to TRAIL by the combination of drugs having a synergistic action with TRAIL is reasonable. In spite of the initial cell resistance showed by CLBL-1 cells, we showed that combination of TRAIL with FVP strongly activates the apoptotic process in CLBL-1 cells, creating the new possibilities of therapeutic strategies based on sensitization to TRAIL in canine cancers.

\section{Conflicts of Interest}

The Authors declare that they have no conflicts of interest regarding this study and article. Luis Martinez-Lostao has filed a patent application (W02011020933) for the use of liposome-bound Apo2L/TRAIL.

\section{Acknowledgements}

This research was supported by statutory research and development activity founds by Minister of Science and Higher Education assigned to Faculty of Veterinary Medicine, Wroclaw University of Environmental and Life Sciences (2016). The Authors are grateful to B.C. Rütgen (Institute of Immunology, Department of Pathobiology, University of Veterinary Medicine Vienna) for providing CLBL-1 cell line. Publication was supported by the Wroclaw Centre of Biotechnology, programme: the Leading National Research Center (KNOW) for years 2014-2018

\section{References}

1 Pitti RM, Marsters SA, Ruppert S, Donahue CJ, Moore A and Ashkenazi A: Induction of apoptosis by Apo-2 ligand, a new member of the tumor necrosis factor cytokine family. J Biol Chem 271: 12687-12690, 1996.

2 Wiley SR, Schooley K, Smolak PJ, Din WS, Huang CP, Nicholl JK, Sutherland GR, Smith TD, Rauch C, Smith CA et al: Identification and characterization of a new member of the TNF family that induces apoptosis. Immunity 3: 673-682, 1995.

3 Anel A, Bosque A, Naval J, Pineiro A, Larrad L, Alava MA and Martinez-Lorenzo M: Apo2L/TRAIL and immune regulation. Front Biosci 12: 2074-2084, 2007.

4 Falschlehner C, Schaefer U and Walczak H: Following TRAIL's path in the immune system. Immunology 127: 145-154, 2009.

5 LeBlanc HN and Ashkenazi A: Apo2L/TRAIL and its death and decoy receptors. Cell Death Differ 10: 66-75, 2003.

6 Lemke J, von Karstedt S, Abd El Hay M, Conti A, Arce F, Montinaro A, Papenfuss K, El-Bahrawy MA and Walczak H: Selective CDK9 inhibition overcomes TRAIL resistance by concomitant suppression of cFlip and Mcl-1. Cell Death Differ 21: 491-502, 2014.

7 de Miguel D, Lemke J, Anel A, Walczak H and Martinez-Lostao L: Onto better TRAILs for cancer treatment. Cell Death Differ 23: 733-747, 2016.

8 Walczak H: Death receptor-ligand systems in cancer, cell death, and inflammation. Cold Spring Harb Perspect Biol 5: a008698, 2013.

9 Holland PM: Targeting Apo2L/TRAIL receptors by soluble Apo2L/TRAIL. Cancer Lett 332: 156-162, 2013.

10 Almasan A and Ashkenazi A: Apo2L/TRAIL: apoptosis signaling, biology, and potential for cancer therapy. Cytokine Growth Factor Rev 14: 337-348, 2003.

11 De Miguel D, Basanez G, Sanchez D, Malo PG, Marzo I, Larrad L, Naval J, Pardo J, Anel A and Martinez-Lostao L: Liposomes decorated with Apo2L/TRAIL overcome chemoresistance of human hematologic tumor cells. Mol Pharm 10: 893-904, 2013.

12 Martinez-Lostao L, de Miguel D, Al-Wasaby S, Gallego-Lleyda A and Anel A: Death ligands and granulysin: mechanisms of tumor cell death induction and therapeutic opportunities. Immunotherapy 7: 883-882, 2015. 
13 Simonet WS, Lacey DL, Dunstan CR, Kelley M, Chang MS, Luthy R, Nguyen HQ, Wooden S, Bennett L, Boone T, Shimamoto G, DeRose M, Elliott R, Colombero A, Tan HL, Trail G, Sullivan J, Davy E, Bucay N, Renshaw-Gegg L, Hughes TM, Hill D, Pattison W, Campbell P, Sander S, Van G, Tarpley J, Derby P, Lee R and Boyle WJ: Osteoprotegerin: a novel secreted protein involved in the regulation of bone density. Cell 89: 309-319, 1997.

14 Yun TJ, Chaudhary PM, Shu GL, Frazer JK, Ewings MK, Schwartz SM, Pascual V, Hood LE and Clark EA: OPG/FDCR1 , a TNF receptor family member, is expressed in lymphoid cells and is up-regulated by ligating CD40. J Immunol 161: 61136121, 1998.

15 Woo KM, Choi Y, Ko SH, Ko JS, Oh KO and Kim KK: Osteoprotegerin is present on the membrane of osteoclasts isolated from mouse long bones. Exp Mol Med 34: 347-352, 2002.

16 De Toni EN, Thieme SE, Herbst A, Behrens A, Stieber P, Jung A, Blum H, Goke B and Kolligs FT: OPG is regulated by betacatenin and mediates resistance to TRAIL-induced apoptosis in colon cancer. Clin Cancer Res 14: 4713-4718, 2008.

17 Elders RC, Baines SJ and Catchpole B: Susceptibility of the C2 canine mastocytoma cell line to the effects of tumor necrosis factor-related apoptosis-inducing ligand (TRAIL). Vet Immunol Immunopathol 130: 11-16, 2009.

18 Spee B, Jonkers MD, Arends B, Rutteman GR, Rothuizen J and Penning LC: Specific down-regulation of XIAP with RNA interference enhances the sensitivity of canine tumor cell-lines to TRAIL and doxorubicin. Mol Cancer 5: 34, 2006.

19 Rong S, Cai JH and Andrews J: Cloning and apoptosis-inducing activities of canine and feline TRAIL. Mol Cancer Ther 7: 21812191, 2008.

20 Elders RC, Holder A, Smith KC, Baines SJ and Catchpole B: Recombinant canine IgE Fc and an IgE Fc-TRAIL fusion protein bind to neoplastic canine mast cells. Vet Immunol Immunopathol 159: 29-40, 2014.

21 Yerbes R, Palacios C and Lopez-Rivas A: The therapeutic potential of TRAIL receptor signalling in cancer cells. Clin Transl Oncol 13: 839-847, 2011.

22 Holland PM: Death receptor agonist therapies for cancer, which is the right TRAIL? Cytokine Growth Factor Rev 25: 185-193, 2014.

23 Micheau O, Shirley S and Dufour F: Death receptors as targets in cancer. Br J Pharmacol 169: 1723-1744, 2013.

24 Stuckey DW and Shah K: TRAIL on trial: preclinical advances in cancer therapy. Trends Mol Med 19: 685-694, 2013.

25 Wajant H, Gerspach J and Pfizenmaier K: Engineering death receptor ligands for cancer therapy. Cancer Lett 332: 163-174, 2013.

26 Bernardi S, Secchiero P and Zauli G: State of art and recent developments of anti-cancer strategies based on TRAIL. Recent Pat Anticancer Drug Discov 7: 207-217, 2012.

27 Hellwig CT and Rehm M: TRAIL signaling and synergy mechanisms used in TRAIL-based combination therapies. Mol Cancer Ther 11: 3-13, 2012.

28 Shanker A, Brooks AD, Tristan CA, Wine JW, Elliott PJ, Yagita H, Takeda K, Smyth MJ, Murphy WJ and Sayers TJ: Treating metastatic solid tumors with bortezomib and a tumor necrosis factor-related apoptosis-inducing ligand receptor agonist antibody. J Natl Cancer Inst 100: 649-662, 2008.
29 Chen MC, Huang HH, Lai CY, Lin YJ, Liou JP, Lai MJ, Li YH, Teng CM and Yang CR: Novel histone deacetylase inhibitor MPT0G009 induces cell apoptosis and synergistic anticancer activity with tumor necrosis factor-related apoptosis-inducing ligand against human hepatocellular carcinoma. Oncotarget 7(1): 402-417, 2016.

30 Rosato RR, Almenara JA, Coe S and Grant S: The multikinase inhibitor sorafenib potentiates TRAIL lethality in human leukemia cells in association with Mcl-1 and cFLIPL downregulation. Cancer Res 67: 9490-9500, 2007.

31 Ang C, O'Reilly EM, Carvajal RD, Capanu M, Gonen M, Doyle L, Ghossein R, Schwartz L, Jacobs G, Ma J, Schwartz GK and AbouAlfa GK: A Nonrandomized, Phase II Study of Sequential Irinotecan and Flavopiridol in Patients With Advanced Hepatocellular Carcinoma. Gastrointest Cancer Res 5: 185-189, 2012.

32 Bible KC, Peethambaram PP, Oberg AL, Maples W, Groteluschen DL, Boente M, Burton JK, Gomez Dahl LC, Tibodeau JD, Isham CR, Maguire JL, Shridhar V, Kukla AK, Voll KJ, Mauer MJ, Colevas AD, Wright J, Doyle LA and Erlichman C: A phase 2 trial of flavopiridol (Alvocidib) and cisplatin in platin-resistant ovarian and primary peritoneal carcinoma: MC0261. Gynecol Oncol 127: 55-62, 2012.

33 Fandy TE, Ross DD, Gore SD and Srivastava RK: Flavopiridol synergizes TRAIL cytotoxicity by downregulation of FLIPL. Cancer Chemother Pharmacol 60: 313-319, 2007.

34 Kim DM, Koo SY, Jeon K, Kim MH, Lee J, Hong CY and Jeong S: Rapid induction of apoptosis by combination of flavopiridol and tumor necrosis factor (TNF)-alpha or TNF-related apoptosisinducing ligand in human cancer cell lines. Cancer Res 63: 621626, 2003.

35 Miyashita K, Shiraki K, Fuke H, Inoue T, Yamanaka Y, Yamaguchi Y, Yamamoto N, Ito K, Sugimoto K and Nakano T: The cyclin-dependent kinase inhibitor flavopiridol sensitizes human hepatocellular carcinoma cells to TRAIL-induced apoptosis. Int J Mol Med 18: 249-256, 2006.

36 Nawrocki ST, Carew JS, Douglas L, Cleveland JL, Humphreys $\mathrm{R}$ and Houghton JA: Histone deacetylase inhibitors enhance lexatumumab-induced apoptosis via a p21Cip1-dependent decrease in survivin levels. Cancer Res 67: 6987-6994, 2007.

37 Palacios C, Yerbes R and Lopez-Rivas A: Flavopiridol induces cellular FLICE-inhibitory protein degradation by the proteasome and promotes TRAIL-induced early signaling and apoptosis in breast tumor cells. Cancer Res 66: 8858-8869, 2006.38 Rosato RR, Dai Y, Almenara JA, Maggio SC, and Grant S: Potent antileukemic interactions between flavopiridol and TRAIL/Apo2L involve flavopiridol-mediated XIAP downregulation. Leukemia 18: 1780-1788, 2004.

39 Taniai M, Grambihler A, Higuchi H, Werneburg N, Bronk SF, Farrugia DJ, Kaufmann SH and Gores GJ: Mcl-1 mediates tumor necrosis factor-related apoptosis-inducing ligand resistance in human cholangiocarcinoma cells. Cancer Res 64 : 3517-3524, 2004.

40 De Miguel D, Gallego-Lleyda A, Ayuso JM, Pawlak A, Conde B, Ochoa I, Fernandez LJ, Anel A and Martinez-Lostao L: Improved Anti-Tumor Activity of Novel Highly Bioactive Liposome-Bound TRAIL in Breast Cancer Cells. Recent Pat Anticancer Drug Discov 11: 197-214, 2016.

41 Ema Y, Igase M, Takeda Y, Yanase T, Umeki S, Hiraoka H, Okuda M and Mizuno T: Investigation of the cytotoxic effect of flavopiridol in canine lymphoma cell lines. Vet Comp Oncol 14(Suppl 1): 95-106, 2015. 
42 Pawlak A, Rapak A, Drynda A, Poradowski D, Zbyryt I, Dzimira S, Suchanski J and Obminska-Mrukowicz B: Immunophenotypic characterization of canine malignant lymphoma: a retrospective study of cases diagnosed in Poland Lower Silesia, over the period 2011-2013. Vet Comp Oncol 1: 52-60, 2016.

43 Rutgen BC, Hammer SE, Gerner W, Christian M, de Arespacochaga AG, Willmann M, Kleiter M, Schwendenwein I and Saalmuller A: Establishment and characterization of a novel canine B-cell line derived from a spontaneously occurring diffuse large cell lymphoma. Leuk Res 34: 932-938, 2010.

44 MacFarlane M, Ahmad M, Srinivasula SM, Fernandes-Alnemri T, Cohen GM and Alnemri ES: Identification and molecular cloning of two novel receptors for the cytotoxic ligand TRAIL. J Biol Chem 272: 25417-25420, 1997.

45 Pawlak A, Ziolo E, Kutkowska J, Blazejczyk A, Wietrzyk J, Krupa A, Hildebrand W, Dziegiel P, Dzimira S, ObminskaMrukowicz B, Strzadala L and Rapak A: A novel canine B-cell leukaemia cell line. Establishment, characterisation and sensitivity to chemotherapeutics. Vet Comp Oncol 9: 12257, 2016.

46 Sedlacek HH: Mechanisms of action of flavopiridol. Crit Rev Oncol Hematol 38: 139-170, 2001.
47 Jouan-Lanhouet S, Arshad MI, Piquet-Pellorce C, Martin-Chouly C, Le Moigne-Muller G, Van Herreweghe F, Takahashi N, Sergent O, Lagadic-Gossmann D, Vandenabeele P, Samson M and Dimanche-Boitrel MT: TRAIL induces necroptosis involving RIPK1/RIPK3-dependent PARP-1 activation. Cell Death Differ 19: 2003-2014, 2012.

48 Lee HR, Chang TH, Tebalt MJ, 3rd, Senderowicz AM and Szabo E: Induction of differentiation accompanies inhibition of $\mathrm{Cdk} 2$ in a non-small cell lung cancer cell line. Int J Oncol 15: 161$166,1999$.

49 Keskin H, Garriga J, Georlette D and Grana X: Complex effects of flavopiridol on the expression of primary response genes. Cell Div 7: 1747-1028, 2012.

50 Roth W and Reed JC: FLIP protein and TRAIL-induced apoptosis. Vitam Horm 67: 189-206, 2004.

51 Ozoren N and El-Deiry WS: Defining characteristics of Types I and II apoptotic cells in response to TRAIL. Neoplasia 4: 551$557,2002$.

Received September 25, 2017

Revised October 13, 2017

Accepted October 17, 2017 